\title{
Predictive value of P300 event-related potential component in early cognitive impairment in patients with uncomplicated newly diagnosed hepatitis $C$ virus
}

\author{
Ahmed Esmael ${ }^{1 *}\left(\mathbb{0}\right.$, Tamer Belal ${ }^{1}$, Ibrahim F. Amer ${ }^{2}$, Eslam Samra ${ }^{3}$, Azza Elmongui ${ }^{1}$ and Saad Shawki ${ }^{4}$
}

\begin{abstract}
Background: Cognitive impairment in patients with hepatitis C virus (HCV) is reported in the early onset of HCV infection without hepatic cirrhosis or marked liver impairment. Methods currently available to identify the risk for early cognitive impairment in hepatitis C virus (HCV) infection do not combine enough sensitivity and specificity. The present study aimed to evaluate the P 300 components of event-related potential (ERP) abnormalities as valid biomarkers for prediction and diagnosis of the cognitive impairment in newly diagnosed hepatitis $C$ virus infection. This study is a case-control involved fifty patients newly diagnosed HCV and fifty age and sex-matched healthy controls. Assessments of cognitive functions were carried out by the Mini-mental State Examination, Wechsler Memory Scale Revised short form, and The Wechsler Adult Intelligence Scale, in addition to estimation of the amplitude and the latency of the P300 by the event-related potentials.
\end{abstract}

Results: Neuropsychological scales suggested the early incidence of cognitive impairment among hepatitis $C$ virus patients. The electrophysiological study showed significant prolongation of P300 latency and decreased amplitude in HCV patients group compared with the control group. A binary logistic regression detected that P 300 latency $\geq 369$ ms was significantly accompanied by a threefold increased risk of impaired cognition (OR 3.09, 95\% Cl 1.59-5.72, $P<0.01$ ), while $P 300$ amplitude $\leq 8.2 \mu \mathrm{v}$ was significantly accompanied by a twofold increased risk of impaired cognition (OR 2.18, 95\% 1.43-4.05, $P<0.01$ ).

Conclusion: This study concluded that the P300 event-related potentials components are valid biomarker as easy, noninvasive assessment and cost-effective method of early cognitive impairment in patients with uncomplicated newly diagnosed hepatitis $C$ virus.

Registration of Clinical Trial Research: ClinicalTrials.gov ID: NCT04389268. https://clinicaltrials.gov/ct2/show/NCT04 389268

Keywords: Hepatitis C virus, Cognitive impairment, Event-related potentials, P300 latency, P300 amplitude

\footnotetext{
${ }^{*}$ Correspondence: deltaneuro@yahoo.com

1 Neurology Department, Faculty of Medicine, Mansoura University,

Mansoura 35516, Egypt

Full list of author information is available at the end of the article
}

\section{Introduction}

Hepatitis $C$ virus infection is estimated to affect 3.5 million people in the USA and 71 million people worldwide [1, 2]. Hepatitis $C$ virus is considered as epidemic infection in Egypt, having the highest prevalence in the world $(14.7 \%)[3,4]$. In these patients, health outcomes are greatly affected by a range of common comorbidities, 
including various types of psychological and cognitive disorders $[5,6]$.

The incidence of cognitive impairment in patients with hepatitis $\mathrm{C}$ virus (HCV) is reported in the early onset of $\mathrm{HCV}$ infection without hepatic cirrhosis or marked liver impairment [7,8]. It was found that $40-74 \%$ of cases infected with the hepatitis $\mathrm{C}$ virus will have one or more extra-hepatic manifestations during the disease [9, 10]. Mild cognitive impairment is among the common extrahepatic manifestations associated with hepatitis $\mathrm{C}$ virus without clear pathophysiological mechanism that explains its incidence [11].

HCV-associated neurocognitive impairment shows a prominent frontal lobe affection with impaired executive functions, disordered working memory, decision-making and impaired verbal fluency [12-14], disinhibited behavior and apathy [15], in addition to mood and emotional disturbances [16]. The neuroimaging studies showed a remarkable affection of the frontal cortico-striatal tracts that coordinate emotion \& motivation, executive functions, and motor activity [17]. Several studies have included patients accompanied by comorbidities that may cause impaired cognition, such as liver cirrhosis, which may cause a bias that affects the results [18]. As Kramer et al. 2002 demonstrated that patients with $\mathrm{HCV}$ infection showed slight but significant neurocognitive impairment, possibly indicating a further extrahepatic manifestation of chronic hepatitis C. However, our study investigated cognitive functions in newly diagnosed hepatitis $C$ virus infection [19].

Event-related potentials (ERPs) are valuable clinical and research tools to investigate the cognitive functions in different neuropsychiatric diseases [20]. The P300 is the most frequently used and defined ERPs component which is a sensitive estimate of neural activity related to attention and memory [21]. Regardless the advanced functional neuroimaging, the ERP estimation is still considered an important tool for brain study and to investigate many neuropsychiatric disorders [22].

Methods currently available to identify the risk for early cognitive impairment usually investigated patients with chronic hepatitis $C$ virus infection [22-25]. The purpose of this study is to evaluate the $\mathrm{P} 300$ component of ERP alterations as a valid biomarker for diagnosis and prediction of the cognitive functions in newly diagnosed hepatitis $C$ virus infection.

\section{Methods}

\section{Study design and participants}

This case-control study was included fifty ( 28 men and 22 women) first diagnosed, therapy naïve, HCV patients, aged 20-50, and recruited from the outpatient clinic and department of gastroenterology and hepatology, or referred to the department of neuropsychiatry Kafr Elsheikh University Hospital. In addition, 50 healthy controls matched for age, sex (26 men and 24 women), educational level, and socioeconomic status were included. The study was done for a 1 year from February 2019 to February 2020. A written informed consent was taken from patients and control before participation. This study was approved by the local ethical committee.

\section{Inclusion and exclusion criteria}

The inclusion criteria included newly diagnosed HCV (no current or previous treatment with interferon), uncomplicated (Child A, score 6) [26]. The exclusion criteria were patients with cirrhosis or complicated $\mathrm{HCV}$ (Child $\mathrm{B} / \mathrm{C}$ ), causes of chronic liver disease (hepatitis B infection, alcohol abuse, parasitic infection, autoimmune disorders, cardiac failure, toxic, and hereditary) psychiatric illness, current substance abuse, renal failure, COPD, uncontrolled DM, other chronic illness that affect cognition (parkinsonism, Alzheimer's, and vascular dementia).

\section{Clinical assessment and investigations}

All participants were subjected to the following: full history taking, general medical examination, and complete neurological examination. Laboratory investigations included: HBV surface antigens, anti-HCV antibodies ( $\mathrm{HCV}$ antibodies done by Beckman colter access immunoassay), PCR viral titer, TSH, random blood glucose, liver function, renal function, and $\mathrm{CBC}$. Abdominal ultrasonography (Philips EPIC 7, Curved probe, $3.5 \mathrm{MHz}$ ) was done for evaluation of the liver and exclusion of hepatic cirrhosis or marked fibrosis. MRI of the brain using multiple sequences and planes without contrast on $3 \mathrm{~T}$ MRI closed machine to exclude neurological causes of cognitive impairment.

\section{Cognitive assessment}

All patients and controls were subjected to cognitive assessment using the following tests:

\section{Mini-mental state examination (MMSE)}

This is a rapid screening estimate of cognitive functions that evaluates orientation, attention, working memory, learning, naming, construction, comprehension, and repetition. The total score is 30 , with scores less than 24 indicating impaired cognition [27].

\section{Wechsler Memory Scale-Revised (WMS-R) short form}

The aim of the test is to provide estimates of various aspects of memory and learning functions (Rabin et al. 2005). WMS-R includes a group of subtests that evaluates figural memory, logical memory, visual paired associate, visual reproduction, and visual memory span [28]. 


\section{The Wechsler Adult Intelligence Scale (WAIS)-IV Assessment,} 2nd Edition

This test provided estimates of the general intellectual function and focused mainly on the difference between verbal IQ and performance IQ scores, and differential characters of subtest $[28,29]$.

\section{P300 brain wave}

Auditory P300-evoked brain potential represents the brain reaction to variable sensory, cognitive, or mechanical stimuli by focusing on the diverse stimuli among the stereotypical ones (the auditory oddball paradigm) [30]. In the auditory oddball task, persons were subjected to a series of high $(1000 \mathrm{~Hz})$ "task relevant" target tones and lower $(500 \mathrm{~Hz})$ "task irrelevant" tones of $50 \mathrm{~ms}$ duration, increase and decrease time, $5 \mathrm{~ms}, 85 \mathrm{~dB}$, and inter-stimulus interval between 2 and $14 \mathrm{~s}$. The amplitude and the latency of the P300 were estimated by the event-related potentials and the results of $\mathrm{P} 300$ in $\mathrm{HCV}$ patients group were compared with the control group (Fig. 1). The test was conducted utilizing quantitative EMG/EP workstations using a Dantec Keypoint (Medtronic, Denmark) device. The test was performed by adding an odd-ball model, as in a set of standard "repeated" stimuli, the subject has to detect an occasionally target stimulus.

Before commencing the examination, the test was first clarified to the patient. Before the wave was registered, the test was replicated many times to ensure the patient understood the process. All of the patients were able to understand the procedure, and each examination would take about $30 \mathrm{~min}$. From scalp electrodes the evoked potential waves were registered with reference electrode

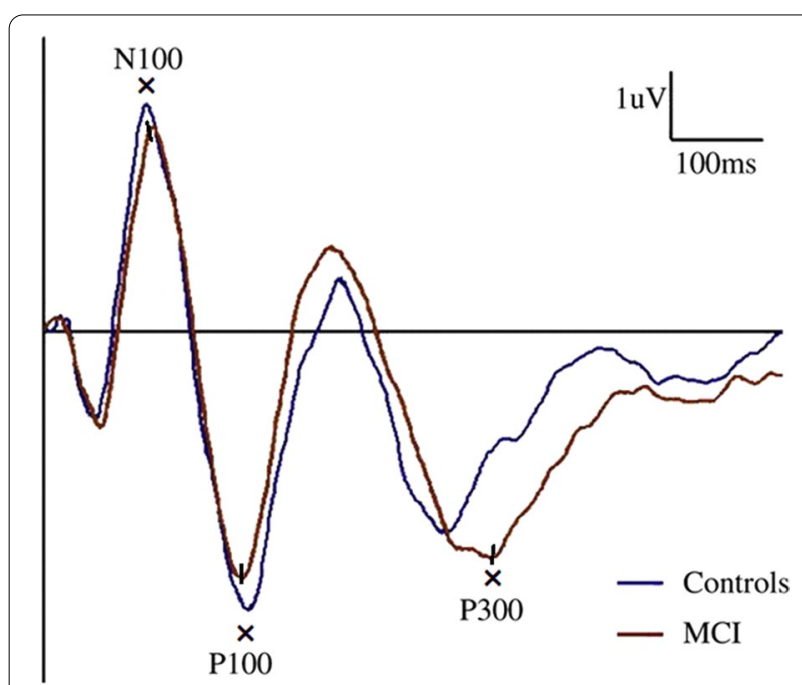

Fig. 1 Auditory ERP response from a HCV patient with $\mathrm{MCl}$ showing a prolonged P300 (P3) latency (405 ms) and low P 300 amplitude (5 uv) position on the ear lobule and a land electrode located on the hand. The active electrode is located along the midline at Oz. The reference electrode is located at location Fz. The subscript $\mathrm{z}$ indicates a midline position. The locations of the lateral active electrodes, $\mathrm{O} 1 \mathrm{O} 2 \mathrm{PO} 7$, and PO 8 are indicated along with the midline active electrode location, $\mathrm{O} \mathrm{Z}$. For delivering the auditory stimulus, headphones had been used completely covered the ears. The waves have been classified as N1, P2, N2, P3, and N3 [31]. The measured variables were the P300 latency associated with cognitive processing speed and wave amplitude associated with memory consolidation [32].

\section{Statistical analysis}

Data were analyzed using the Statistical Package of Social Science (SPSS) program for Windows (simple edition of the software 21). Qualitative information was described utilizing numbers and percent. Categorical variables were compared by the Chi-square test and Fischer exact test was utilized when expected cell count less than 5. Continuous variables were shown as mean \pm SD (standard deviation) for parametric information and median (min$\max$ ) for non-parametric information. $\mathrm{HCV}$ patients group were compared with the control group by Student $t$ test used for parametric information and Mann Whitney test used for non-parametric information.

Pearson correlation was used to correlate parametric data continuously while using Spearman correlation to correlate non-parametric data continuously. Cutoff points for $\mathrm{P} 300$ latency and amplitude were determined by the ROC curve. Finally, a binary logistic regression analysis was done to establish the ability of the determined cutoff values of P300 latency and amplitude to predict the early cognitive impairment in $\mathrm{HCV}$ patients. The threshold of significance is set as a $P$ value $<0.05$.

\section{Results \\ Patient characteristics}

No significant differences were found between the patients with $\mathrm{HCV}$ infection and controls regarding age, gender, marital status, occupation, level of education and socioeconomic status (Table 1).

\section{Early cognitive impairment in HCV patients (Table 2)}

Impaired cognition was detected in $7(14 \%)$ of the patients. All subtests of the Wechsler memory test scale showed significant lower scores in cases compared with controls suggesting cognitive impairment among hepatitis $C$ virus patients; figural memory $(7.09 \pm 1.19$ versus $9.02 \pm 0.87, P<0.001)$, logical memory $(26.10 \pm 2.10$ versus $28.48 \pm 1.51, P<0.001$ ), visual paired association (15.76 \pm 1.45 versus $17.32 \pm 0.96, P=0.025)$, visual Reproduction ( $35.02 \pm 1.88$ versus $39.46 \pm 1.59, P<0.001)$, and 
Table 1 Socio-demographic data among studied groups

\begin{tabular}{|c|c|c|c|c|}
\hline Socio -demographic data & Cases group $(n=50)$ & Control group $(n=50)$ & Test of significance & $P$-value \\
\hline \multicolumn{5}{|l|}{ Age/years } \\
\hline Mean $\pm S D$ & $34.40 \pm 9.56$ & $34.68 \pm 9.18$ & $t=0.149$ & 0.882 \\
\hline Min-Max & $20-50$ & $22-50$ & & \\
\hline \multicolumn{5}{|l|}{ Sex } \\
\hline Male & $28(56 \%)$ & $26(52 \%)$ & $x^{2}=0.161$ & 0.688 \\
\hline Female & $22(44 \%)$ & $24(48 \%)$ & & \\
\hline \multicolumn{5}{|l|}{ Marital status } \\
\hline Single & $22(44 \%)$ & $20(40 \%)$ & $x^{2}=0.164$ & 0.685 \\
\hline Married & $28(56 \%)$ & $30(60 \%)$ & & \\
\hline \multicolumn{5}{|l|}{ Occupation } \\
\hline Non worker/housewife & $20(40 \%)$ & $24(48 \%)$ & & \\
\hline Office worker & $13(26 \%)$ & $16(32 \%)$ & $x^{2}=2.48$ & 0.288 \\
\hline Manual worker & $17(34 \%)$ & $10(20 \%)$ & & \\
\hline \multicolumn{5}{|l|}{ Education } \\
\hline Primary school & $8(16 \%)$ & $7(14 \%)$ & & \\
\hline Secondary school & $14(28 \%)$ & $12(24 \%)$ & $x^{2}=0.446$ & 0.93 \\
\hline Tertiary school & $9(18 \%)$ & $11(22 \%)$ & & \\
\hline University education & $19(38 \%)$ & $20(40 \%)$ & & \\
\hline \multicolumn{5}{|l|}{ Impaired cognition } \\
\hline Number (\%) (MMSE $\leq 23)$ & $7(14 \%)$ & 0 & - & - \\
\hline
\end{tabular}

$x^{2}$ Chi square test, $t$ :Student $t$-test

Table 2 Cognitive impairment in HCV patients

\begin{tabular}{|c|c|c|c|c|}
\hline & Cases group $(n=50)$ & Control group $(n=50)$ & $t$-test & $P$ value \\
\hline \multicolumn{5}{|l|}{ Wechsler memory test scale } \\
\hline Figural memory & $7.09 \pm 1.19$ & $9.02 \pm 0.87$ & 4.88 & $<0.001^{*}$ \\
\hline Logical memory & $26.10 \pm 2.10$ & $28.48 \pm 1.51$ & 3.76 & $<0.001^{*}$ \\
\hline Visual paired association & $15.76 \pm 1.45$ & $17.32 \pm 0.96$ & 2.28 & $=0.025^{*}$ \\
\hline Visual reproduction & $35.02 \pm 1.88$ & $39.46 \pm 1.59$ & 9.87 & $<0.001^{*}$ \\
\hline Visual MEMORY SPAN & $22.04 \pm 1.72$ & $25.08 \pm 1.26$ & 6.75 & $<0.001^{*}$ \\
\hline \multicolumn{5}{|c|}{ Wechsler Adult Intelligence Scale } \\
\hline Verbal IQ & $103.52 \pm 6.78$ & $108.74 \pm 2.67$ & 5.06 & $<0.001^{*}$ \\
\hline Performance IQ & $103.08 \pm 6.16$ & $108.30 \pm 3.06$ & 5.36 & $<0.001^{*}$ \\
\hline Full scale IQ & $102.78 \pm 5.31$ & $108.74 \pm 2.55$ & 7.15 & $<0.001^{*}$ \\
\hline \multicolumn{5}{|c|}{ Mini-mental status examination } \\
\hline & $23.68 \pm 1.66$ & $28.40 \pm 1.28$ & 5.81 & $<0.001^{*}$ \\
\hline
\end{tabular}

${ }^{*}$ significant $\mathrm{p}<0.05$

Visual memory span $(22.04 \pm 1.72$ versus $25.08 \pm 1.26$, $P<0.001)$. The verbal, performance, and full scale IQ items of the Wechsler Adult Intelligence Scale were significantly impaired among HCV patients, as compared to control group $(103.52 \pm 6.78$ versus $108.74 \pm 2.67$, $P<0.001$ and $103.08 \pm 6.16$ versus $108.30 \pm 3.06, P<0.001$ and $102.78 \pm 5.31$ versus $108.74 \pm 2.55, \mathrm{P}<0.001$, respectively). In addition, the mini-mental state examination was significantly decreased among $\mathrm{HCV}$ patients in comparison with the control group $(23.68 \pm 1.66$ versus $28.40 \pm 1.28, P<0.001)$.

\section{P 300 latency and amplitude in HCV patients}

The electrophysiological study showed significantly prolonged P300 latency in $\mathrm{HCV}$ patients group compared with the control group (379.32 \pm 22.73 versus $318.82 \pm 12.25, \quad P<0.001)$ and reduced amplitude in 
HCV patients group compared with the control group $(8.23 \pm 1.20$ versus $12.13 \pm 0.93, P<0.001)$ (Fig. 2$)$.

\section{Correlation between P300 and cognition}

The increase of P 300 latency was associated with decrease of all the subtests of Wechsler memory test scale, Wechsler Adult Intelligence Scale, and MMSE. There was a significant negative correlation between P300 latency and all subtests of Wechsler memory test scale; figural memory $(r=-0.48, P=0.02)$, logical memory $(r=-0.41, P=0.03)$, visual paired association $(r=-0.39$, $P=0.04)$, visual reproduction $(r=-0.67, P=0.001)$, and visual memory span $(r=-0.63, P=0.002)$. In addition, there was a significant negative correlation between P300 latency and all subtests of Wechsler Adult Intelligence Scale; verbal IQ $(r=-0.52, P=0.01)$, performance IQ ( $r=-0.54, P=0.01)$, full scale IQ $(r=-0.68, P=0.001)$. Similarly, there was a significant inverse correlation between P300 latency and MMSE $(r=-0.66, P=0.001)$ (Table 3).

The decrease of the P300 amplitude was associated with decrease of all the subtests of Wechsler memory test scale, Wechsler Adult Intelligence Scale, and MMSE. There was a significant positive correlation between P300 amplitude and all subtests of Wechsler memory test scale; figural memory $(r=0.45, P<0.05)$, logical memory $(r=0.42, P<0.05)$, visual paired association $(r=0.37$, $P<0.05)$, visual reproduction $(r=0.61, P<0.005)$, and visual memory $\operatorname{span}(r=0.54, P<0.01)$. In addition, there was a significant positive correlation between P300 amplitude and all subtests of Wechsler Adult Intelligence Scale; verbal IQ $(r=0.51, P<0.01)$, performance IQ $(r=0.50, P<0.01)$, full scale IQ $(r=0.63, P<0.005)$. Similarly, there was a significant negative correlation
Table 3 Correlation between P300 latancy and cognition

\begin{tabular}{lll}
\hline Variables & P 300 LAT & \\
\cline { 2 - 3 } & $\mathbf{r}$ & $\mathbf{p}$ \\
\hline Wechsler memory test scale & & \\
$\quad$ Figural memory & -0.48 & $0.02^{*}$ \\
Logical memory & -0.41 & $0.03^{*}$ \\
Visual paired association & -0.39 & $0.04^{*}$ \\
Visual reproduction & -0.67 & $0.001^{*}$ \\
Visual memory span & -0.63 & $0.002^{*}$ \\
Wechsler Adult Intelligence Scale & & \\
Verbal IQ & -0.52 & $0.01^{*}$ \\
Performance IQ & -0.54 & $0.01^{*}$ \\
Full scale IQ & -0.68 & $0.001^{*}$ \\
Mini mental status examination & -0.66 & $0.001^{*}$ \\
\hline
\end{tabular}

* mean significant

between P300 amplitude and MMSE $(r=-0.60, P<0.01)$ (Table 4).

\section{Prediction of the impairment of cognition}

The cutoff value of the P 300 latency was equal to $369 \mathrm{~ms}$ with sensitivity and specificity more than $70 \%$ and the cutoff value of the P 300 amplitude was equal to $8.2 \mu \mathrm{v}$ with sensitivity and specificity more than $70 \%$ (Table 5 ). The total performance of the cutoff values detected by the ROC curve for the P 300 latency was 0.89 (95\% CI $0.72-0.95)$ and the P 300 amplitude was 0.84 (95\% CI 0.68-0.89) (Fig. 3). Finally, binary logistic regression demonstrated that $\mathrm{P} 300$ latency $\geq 369 \mathrm{~ms}$ was significantly accompanied by a three times an increase of impaired cognition (OR 3.09, 95\% CI 1.59-5.72, $P<0.01$ ), while P 300 amplitude $\leq 8.2 \mu \mathrm{v}$ was significantly accompanied by a) Mean latency among participants

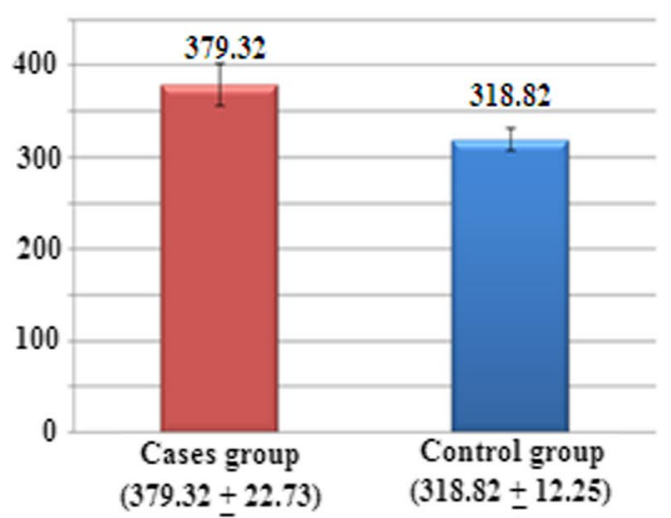

\section{b) Mean P 300 amplitude among particepants}

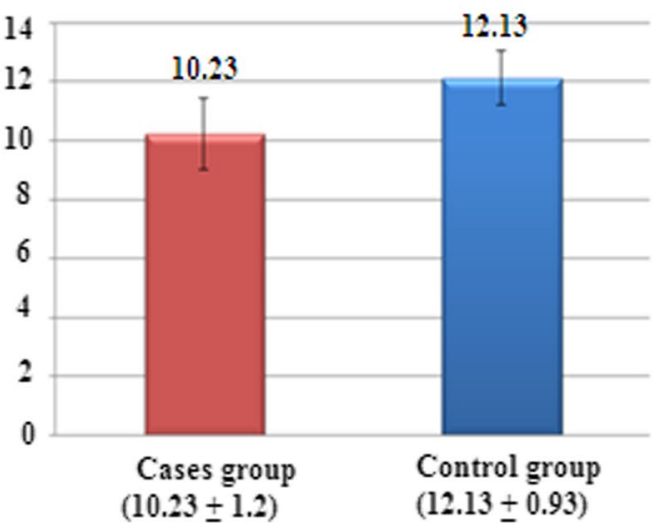

Fig. 2 Average P300 latency and P 300 amplitude in HCV patients compared with P300 latency and P 300 amplitude in healthy controls 
Table 4 Correlation between P 300 amplitude and cognition

\begin{tabular}{lll}
\hline Variables & \multicolumn{2}{l}{ P $\mathbf{3 0 0}$ Amplitude } \\
\cline { 2 - 3 } & $\boldsymbol{r}$ & $\boldsymbol{P}$ \\
\hline Wechsler memory test scale & & \\
Figural memory & 0.45 & $<0.05^{*}$ \\
Logical memory & 0.42 & $<0.05^{*}$ \\
Visual paired association & 0.37 & $<0.05^{*}$ \\
Visual reproduction & 0.61 & $<0.005^{*}$ \\
Visual memory span & 0.54 & $<0.01^{*}$ \\
Wechsler Adult Intelligence Scale & & $<0.01^{*}$ \\
Verbal IQ & 0.51 & $<0.01^{*}$ \\
Performance IQ & 0.50 & $<0.005^{*}$ \\
Full scale IQ & 0.63 & $<0.005^{*}$ \\
Mini mental status examination & 0.60 & \\
\hline
\end{tabular}

a two times an increase of impaired cognition (OR 2.18, 95\% 1.43-4.05, $P<0.01$ ) (Table 6).

\section{Discussion}

Hepatitis $\mathrm{C}$ virus ( $\mathrm{HCV}$ ) infection is a major health problem around the world [33]. The neurocognitive impairments in HCV are frequently subclinical [34], mostly happen in patients infected with $\mathrm{HCV}$ independent of the severity of the hepatic condition or the activity of $\mathrm{HCV}$ infection [17], and precedes the process of cirrhosis and were not related to the viral load titer or the genotype $[35,36]$. Impaired cognition in HCV infection has been found in many studies [7, 8], but few reports not confirming such an association. Cordoba et al. 2003 and Soogoor et al. 2006 reports denied any correlation between $\mathrm{HCV}$ and cognition [37, 38]. However, Córdoba et al. collected his sample from blood donation patients, while Soogoor et al. had a very young aged sample which means the two cases are in the early phase of the illness. In addition, Abrantes et al. 2013 failed to demonstrate proof of a relationship between HCV infection and impaired cognition. However, the few number of patients included in this study may have influenced the results [39].

Our study investigated the cognitive impairment in newly diagnosed $\mathrm{HCV}$ patients with no comorbidities or liver cirrhosis that can affect cognition. To our knowledge it is the first study to determine the cut off values of

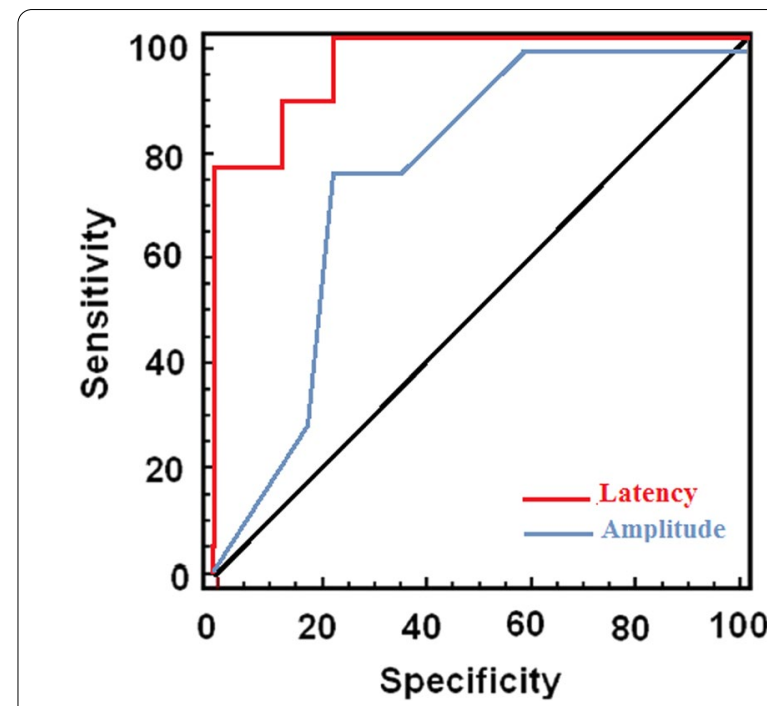

Fig. 3 Receiver operating characteristic (ROC) curves for the detection of the cut-off values of $\mathrm{P} 300$ latency and amplitude for prediction of the impaired cognition in HCV patients

Table 6 Cutoff values of P 300 latency and amplitude for the impaired cognition in HCV patients

\begin{tabular}{llllll}
\hline & Method & Cutoff value & OR & $\mathbf{9 5 \%} \mathrm{Cl}$ & $\boldsymbol{P}$ value \\
\hline P 300 latency & $\begin{array}{l}\text { Youden's } \\
\text { Index }\end{array}$ & $\geq 369$ & 3.09 & $1.59-5.72$ & $<0.01$ \\
$\begin{array}{l}\text { P 300 ampli- } \\
\text { tude }\end{array}$ & $\begin{array}{l}\text { Youden's } \\
\text { Index }\end{array}$ & $\leq 8.2$ & 2.18 & $1.43-4.05$ & $<0.01$ \\
\hline
\end{tabular}

P300 latency and amplitude for prediction of early cognitive impairment in newly diagnosed $\mathrm{HCV}$ patients.

\section{Early cognitive impairment in $\mathrm{HCV}$ patients}

In our study, mild impaired cognition was detected in 7 $(14 \%)$ of the patients and the mini-mental state examination was significantly lower in $\mathrm{HCV}$ patients compared to normal control $(23.68 \pm 1.66$ versus $28.40 \pm 1.28$, $P<0.005)$. Similarly, a study of a large population of chronic HCV patients has revealed the incidence of subclinical impaired cognition in $18 \%$ of patients [40]. While other studies found a higher cognitive impairment in about one-third of HCV individuals [41-43]. Our study

Table 5 Prediction of the cognitive impairment in HCV patients regarding to the $\mathrm{P} 300$

\begin{tabular}{|c|c|c|c|c|c|c|}
\hline & Cut off & Sensitivity & Specificity & PPV & NPV & $P$ value \\
\hline $\begin{array}{l}\text { P } 300 \\
\text { Latency }\end{array}$ & $369 \mathrm{~ms}$ & 0.80 & 0.95 & 0.88 & 0.74 & $<0.01$ \\
\hline $\begin{array}{l}\text { P } 300 \\
\text { Amplitude }\end{array}$ & $8.2 \mu \mathrm{v}$ & 0.70 & 0.88 & 0.83 & 0.71 & $<0.01$ \\
\hline
\end{tabular}


included only the newly diagnosed $\mathrm{HCV}$ patients and a younger age group (20-50), with the exclusion of liver fibrosis \& cirrhosis, and drug abuse, so it was expected that cognitive impairment will be less than the previous studies that included more chronic hepatitis, cirrhosis, and older age patients, for example, Monaco et al. 2015 included in their study patients with advanced liver impairment, alcohol intake, and drug abuse [41].

In our study, the Wechsler Adult Intelligence Scale was significantly impaired among HCV patients and all subtests of the Wechsler Memory scale were significantly diminished in HCV compared to normal controls $(P<0.001)$. Similarly the study of Weissenborn and his colleagues 2004 found that the mean WAIS-R verbal score was significantly higher in the healthy controls than in the HCV infected patients [42]. In addition to the study of Abo Hagar and his colleagues 2018 detected that all subtests of the Wechsler Memory Scale were statistically higher except verbal memory score [43].

\section{Event-related potentials}

Event-related potentials (ERPs) are safe and simple tools for examining the processing of data and cognitive functions, such as attention, learning, memory, and decision-making [44, 45]. Sutton et al. 1965 were the first to reveal evoked potentials with its peak amplitude at about $300 \mathrm{~ms}$ and detected a strong relationship between evoked potentials and cognition [46]. In this manner, it has been distinguished by numerous investigations that impaired cognition in different brain diseases, such as Alzheimer dementia, Parkinsonism, epilepsy, and cerebrovascular stroke, can be evaluated by ERPs [47-50].

\section{P 300 latency and amplitude in HCV patients}

In our study, the electrophysiological study showed significantly prolonged P300 latency in HCV patients group compared with the control group (379.32 \pm 22.73 versus $318.82 \pm 12.25, P<0.001)$ and reduced amplitude in $\mathrm{HCV}$ patients group compared with the control group $(8 \pm 1.20$ versus $12.13 \pm 0.93, P<0.001)$. Likewise, Kramer et al. 2002 found that $16 \%$ of patients of HCV had abnormal P300 latencies not related to the hepatic severity. This finding may reflect impaired information processing speed, reaction time, and the attention paid to a stimulus [23].

\section{$P \mathbf{3 0 0}$ and cognition in HCV patients}

ERPs are sensitive procedure more than psychometric tests in recognition of initial changes in the brain function of hepatic patients, that is why this neurophysiological approach has to be applied clinically [51]. In our study, the increase of P 300 latency was associated with a significant negative correlation with all the subtests of the Wechsler memory test scale, Wechsler Adult Intelligence Scale, and MMSE. While there was a significant positive correlation between the decreased P300 amplitude and all the subtests of the Wechsler memory test scale, Wechsler Adult Intelligence Scale, and MMSE. The amplitude and latency of the P300 wave give data about the processing of the cognitive functions [49]. Longer latencies mean inferior mental performance relative to shorter latencies [52]. P 300 amplitude appears to reflect stimulus data processing and the more attention produces larger P 300 waves [53, 54]. ERP establishes a millisecond-by-millisecond recording of neural processing of certain responses, such as sensory encoding and working memory. Accordingly, it gives a noninvasive tool to assess the brain functions in cognitive disorders [54]. The utilization of P300 for estimation of brain information processing avoids the bias of certain factors, for example, fatigue or depression that can affect the neuropsychological tests. In addition, P300 considers a sensitive marker of impaired higher cognitive functions [36, 51].

In our study, the cutoff value of the P 300 latency was equal to $369 \mathrm{~ms}$ and the cutoff value of the P 300 amplitude was equal to $8.2 \mu \mathrm{v}$ with sensitivity and specificity more than $70 \%$. P 300 latency $\geq 369 \mathrm{~ms}$ was accompanied by a three times an increase of impaired cognition and $\mathrm{P}$ 300 amplitude $\leq 8.2 \mu \mathrm{v}$ was accompanied by a two times an increase of impaired cognition.

\section{Limitations of the study}

The small size of the sample, the absence of liver biopsy as an important tool of evaluation of liver state, and the absence of advanced functional neuroimaging were a group of study limitations that should be considered in the future work about that issue.

\section{Conclusions}

Our findings suggested that the combined use of sensitive neuropsychological scales and the analysis of the P300 may offer a valuable method for the diagnosis of impaired cognition in patients with HCV. P300 eventrelated potentials components are valid biomarker as easy, noninvasive assessment and cost-effective method of early cognitive impairment in patients with uncomplicated newly diagnosed hepatitis $C$ virus.

\section{Abbreviations}

CBC: Complete blood count; ERP: Event-related potential; HBV: Hepatitis B virus; HCV: Hepatitis C virus; MMSE: Mini-mental state examination; MRI: Magnetic resonance imaging; PCR: Polymerase chain reaction; SPSS: Statistical Package of Social Science; TSH: Thyroid-stimulating hormone; WAIS: Wechsler Adult Intelligence Scale; WMS-R: Wechsler Memory Scale-Revised.

\footnotetext{
Acknowledgements

None.
} 


\section{Authors' contributions}

AE: Conceptualization, Methodology, Investigation, Writing —original draft, Writing review and editing. TB: Conceptualization, Methodology, Investigation, Project administration. IA: Conceptualization, Methodology, Investigation, Analysis. ES: Conceptualization, Methodology, Investigation, Interpretation. AE: Conceptualization, Investigation, Project administration, Visualization, Writing original draft, Writing — review and editing. SS: Conceptualization, Methodology, Investigation, Interpretation. All authors have read and approved the final manuscript.

\section{Funding}

This study received no funding

\section{Availability of data and materials}

The datasets generated and analyzed during the current study are not publicly available due to institutional limitations, yet they are available from the corresponding author on reasonable request.

\section{Declarations}

\section{Ethics approval and consent to participate}

All procedures performed in this study were in accordance with the ethical standards of the institutional and/or national research committee and with the 1964 Helsinki declaration. Informed written consent was obtained from all individual participants included in the study. This study was approved by Mansoura Faculty of Medicine Institutional Research Board ("MFM-IRB").

\section{Consent for publication}

Not applicable.

\section{Competing interests}

The authors declare that they have no competing interests.

\section{Author details}

${ }^{1}$ Neurology Department, Faculty of Medicine, Mansoura University, Mansoura 35516, Egypt. ${ }^{2}$ Hepatology and Infectious Diseases Department, Faculty of Medicine, Kafr Elsheikh University, Kafr Elsheikh, Egypt. ${ }^{3}$ Neuropsychiatry Department, Faculty of Medicine, Kafr Elsheikh University, Kafr Elsheikh, Egypt. ${ }^{4}$ Neuropsychiatry Department, Faculty of Medicine, Port-Said University, Port Fouad City, Egypt.

Received: 6 September 2021 Accepted: 14 January 2022

Published online: 29 January 2022

\section{References}

1. Hepatitis C. World Health Organization website. 2019. https://www. who.int/news-room/fact-sheets/detail/hepatitis-c. Accessed 10 Feb 2021.

2. Latt NL. Update on the management of hepatitis C virus infection in the setting of chronic kidney disease and kidney transplantation. Gastroenterol Hepatol (NY). 2018;14(12):687-705.

3. Blach S, Zeuzem S, Manns M, et al. Global prevalence and genotype distribution of hepatitis C virus infection in 2015: a modeling study. Lancet Gastroenterol Hepatol. 2017;2(3):161-76.

4. Waked I, Doss W, El-Sayed M, et al. The current and future disease burden of chronic hepatitis C virus infection in Egypt. Arab J Gastroenterol. 2014;15(2):45-52

5. Barreira DP, Marinho RT, Bicho M, Fialho R, Ouakinin SRS. Psychosocial and neurocognitive factors associated with hepatitis C -implications for future health and wellbeing. Front Psychol. 2019;9:2666

6. Louie KS, St Laurent S, Forssen UM, et al. The high comorbidity burden of the hepatitis C virus-infected population in the United States. BMC Infect Dis. 2012;12:86

7. Yarlott L, Heald E, Forton D. Hepatitis C virus infection, and neurological and psychiatric disorders. J Adv Res. 2017;8(2):139-48. https://doi.org/10. 1016/j.jare.2016.09.005.
8. Senzolo M, Schiff S, D'Aloiso CM, et al. Neuropsychological alterations in hepatitis $C$ infection: the role of inflammation. World J Gastroenterol. 2011:17(29):3369-74.

9. Abrantes J, Torres DS, Brandão-Mello CE. The many difficulties and subtleties in the cognitive assessment of chronic hepatitis C infection. Int J Hepatol. 2020;2020(19):9675235. https://doi.org/10.1155/2020/9675235.

10. Cacoub P, Gragnani L, Comarmond C, Zignego AL. Extrahepatic manifestations of chronic hepatitis $C$ virus infection. Dig Liver Dis. 2014:46:165-73.

11. Zignego AL, Gragnani L, Giannini C, Laffi G. The hepatitis C virus infection as a systemic disease. Intern Emerg Med. 2012;7(3):201-8.

12. De Almeida SM, de Pereira AP, Pedroso MLA, et al. Neurocognitive impairment with hepatitis C and HIV co-infection in Southern Brazil. J Neurovirol. 2018;24:339-49. https://doi.org/10.1007/s13365-018-0617-5.

13. Dirks M, Haag K, Pflugrad H, et al. Neuropsychiatric symptoms in hepatitis C patients resemble those of patients with autoimmune liver disease but are different from those in hepatitis B patients. J Viral Hepat. 2019;26:42231. https://doi.org/10.1111/jvh.12979.

14. Yeoh SW, Holmes ACN, Saling MM, et al. Depression, fatigue, and neurocognitive deficits in chronic hepatitis C. Hepatol Int. 2018;12:294-304.

15. Posada C, Moore DJ, Woods SP, et al. HIV Neurobehavioral Research Center Group Implications of hepatitis C virus infection for behavioral symptoms and activities of daily living. J Clin Exp Neuropsychol. 2010;32:637-44. https://doi.org/10.1080/13803390903418900.

16. Carrozzino D, Porcelli P. Alexithymia in gastroenterology and hepatology: a systematic review. Front Psychol. 2018;9:1-24. https://doi.org/10.3389/ fpsyg.2018.00470.

17. Tagliapietra M, Monaco S. Neuroimaging findings in chronic hepatitis $C$ virus infection: correlation with neurocognitive and neuropsychiatric manifestations. Int J Mol Sci. 2020;21(7):2478. https://doi.org/10.3390/ ijms21072478.

18. Negro, Forton D, Craxì A, Sulkowski MS, Feld JJ, Manns MP. Extrahepatic morbidity and mortality of chronic hepatitis C. Gastroenterology. 2015;149(6):1345-60.

19. Kramer L, Bauer E, Funk $G$, et al. Subclinical impairment of brain function in chronic hepatitis C infection. J Hepatol. 2002;37(3):349-54. https://doi. org/10.1016/s0168-8278(02)00172-1.

20. Sowndhararajan K, Kim M, Deepa P, Park SJ, Kim S. Application of the P300 event-related potential in the diagnosis of epilepsy disorder: a review. Sci Pharm. 2018:86(2):10. https://doi.org/10.3390/scipharm86020010.

21. Eren G, Sevgi T, Nursel E. Visual event-related potentials in patients with mild cognitive impairment. Int J Gerontol. 2016;10(4):190-2.

22. Sokhadze EM, Casanova MF, Casanova E, et al. Event-related potentials (ERP) in cognitive neuroscience research and applications. NeuroRegulation. 2017;4(1):14-27. https://doi.org/10.15540/nr.4.1.14.

23. Yarlott $L$, Heald $E$, Forton D. Hepatitis $C$ virus infection, and neurological and psychiatric disorders - a review. J Adv Res. 2017;8(2):139-48. https:// doi.org/10.1016/j.jare.2016.09.005

24. Fortini I, Arouca EMG, Tengam FM, Nitrini R. Chronic HCV infection and neuropsychiatric dysfunction. eNeurologicalsci. 2019;17:100206. https:// doi.org/10.1016/j.ensci.2019.100206.

25. Abrantes J, Torres DS, Brandão-Mello CE. The many difficulties and subtleties in the cognitive assessment of chronic hepatitis C infection. Int J Hepatol. 2020;2020:9675235. https://doi.org/10.1155/2020/9675235.

26. Child CG, Turcotte JG. Surgery and portal hypertension. In: Child CG, editor. The liver and portal hypertension. Philadelphia: Saunders; 1964. p. 50-64.

27. Shen YJ, Wang WA, Huang FD, et al. The use of MMSE and MoCA in patients with acute ischemic stroke in clinical. Int J Neurosci. 2016:126:442-7. https://doi.org/10.3109/00207454.2015.1031749.

28. Milberg WP, Hebben N, Kaplan E. The Boston process approach to neuropsychological assessment. In: Grant I, Adams KM, editors. Neuropsychological assessment of neuropsychiatric and neuromedical disorders. 3rd ed. Oxford: Oxford University Press; 2009. p. 49.

29. Lichtenberger EO, Kaufman AS. Essentials of WAIS-IV assessment essentials of psychological assessment. 2nd ed. Hoboken NJ: Wiley; 2009. p. 27.

30. Polich J, Kok A. Cognitive and biological determinants of P300: an integrative review. Biol Psychol. 1995:41:103-46.

31. Polich J. Updating P300: an integrative theory of P3a and P3b. Clin Neurophysiol. 2007;118(10):2128-48. https://doi.org/10.1016/j.clinph.2007.04. 019. 
32. Chapman RM, Bragdon HR. Evoked responses to numerical and nonnumerical visual stimuli while problem solving. Nature. 1964;203:1155-7.

33. Zalai $D$, Sherman M, McShane $K$, et al. The importance of fatigue cognitions in chronic hepatitis C infection. J Psychosom Res. 2015;78:193-8.

34. Horváth G, Keleti T, Makara M, et al. Neurocognitive functions in patients with hepatitis C infection. Ideggyogy Sz. 2020;73(1-2):43-9. https://doi. org/10.18071/isz.73.0043.

35. Forton DM, Allsop JM, Main J, et al. Evidence for a cerebral effect of the hepatitis C virus. Lancet. 2001;358(9275):38-9.

36. Forton DM, Thomas HC, Murphy CA. Hepatitis $C$ and cognitive impairment in a cohort of patients with mild liver disease. Hepatology. 2002:35:433-9.

37. Córdoba J, Flavià M, Jacas C, et al. Quality of life and cognitive function in hepatitis C at different stages of liver disease. J Hepatol. 2003;39:231-8.

38. Soogoor M, Lynn HS, Donfield SM, et al. Hemophilia growth and development study. Hepatitis $C$ virus infection and neurocognitive function. Neurology. 2006;24:1482-5

39. Abrantes J, Torres DS, de Mello CE. Patients with hepatitis C infection and normal liver function: an evaluation of cognitive function. Postgrad Med J. 2013:89:433-9.

40. Monaco S, Ferrari S, Gajofatto A, et al. HCV-related nervous system disorders. Clin Dev Immunol. 2012. https://doi.org/10.1155/2012/236148.

41. Monaco S, Mariotto S, Ferrari S, et al. Hepatitis C virus-associated neurocognitive and neuropsychiatric disorders: advances in 2015. World J Gastroenterol. 2015;21(42):11974-83. https://doi.org/10.3748/wjg.v21.i42. 11974.

42. Hilsabeck RC, Hassanein TI, Carlson MD, et al. Cognitive functioning and psychiatric symptomatology in patients with chronic hepatitis C.J Int Neuropsychol Soc. 2003:9:847-54

43. Fontana R, Bieliauskas L, Lindsay K, et al. Cognitive function does not worsen during pegylated interferon and ribavirin retreatment of chronic hepatitis C. Hepatology. 2007:45:1154-63.

44. Kayser J, Tenke CE. Issues and considerations for using the scalp surface Laplacian in EEG/ERP research: a tutorial review. Int J Psychophysiol. 2015;97:189-209. https://doi.org/10.1016/j.ijpsycho.2015.04.012.

45. Patel SH, Azzam PN. Characterization of N200 and P300: selected studies of the event-related potential. Int J Med Sci. 2005;2:147-54. https://doi. org/10.7150/ijms.2.147.

46. Sutton S, Braren M, Zubin J, John ER. Evoked-potential correlates of stimulus uncertainty. Science. 1965;150:1187-8. https://doi.org/10.1126/scien ce.150.3700.1187

47. Morrison C, Rabipour S, Taler V, et al. Visual event-related potentials in mild cognitive impairment and Alzheimer's disease: a literature review. Curr Alzheimer Res. 2019;16:67-89. https://doi.org/10.2174/1567205015 666181022101036.

48. Lei J, Conradi N, Abel C, Frisch S, et al. Cognitive effects of rhythmic auditory stimulation in Parkinson's disease: a P300 study. Brain Res. 2018;1716:70-9. https://doi.org/10.1016/j.brainres.2018.05.016.

49. Casali RL, Amaral MI, Boscariol M, et al. Comparison of auditory eventrelated potentials between children with benign childhood epilepsy with centrotemporal spikes and children with temporal lobe epilepsy. Epilepsy Behav. 2016;59:111-6. https://doi.org/10.1016/j.yebeh.2016.03.024.

50. Hsu LC, Lo SF, Lin CY, et al. Impact of putamen stroke on task context updating: evidence from P300 brain waves. J Clin Neurosci. 2018;55:4551. https://doi.org/10.1016/j.jocn.2018.07.004.

51. Ciećko-Michalska I, Senderecka M, Szewczyk J, et al. Event-related cerebral potentials for the diagnosis of subclinical hepatic encephalopathy in patients with liver cirrhosis. Adv Med Sci. 2006;51:273-7.

52. Vecchio F, Maatta S. The use of auditory event-related potentials in Alzheimer's disease diagnosis. Int J Alzheimers Dis. 2011;2011:653173. https:// doi.org/10.4061/2011/653173.

53. Fabiani $M$, Karis $D$, Donchin E. Effects of mnemonic strategy manipulation in a Von Restorff paradigm. Electroencephalogr Clin Neurophysiol. 1990:75:22-35. https://doi.org/10.1016/0013-4694(90)90149-E.

54. Sur S, Sinha VK. Event-related potential: an overview. Ind Psychiatry J. 2009:18(1):70-3. https://doi.org/10.4103/0972-6748.57865.

\section{Publisher's Note}

Springer Nature remains neutral with regard to jurisdictional claims in published maps and institutional affiliations.

\section{Submit your manuscript to a SpringerOpen ${ }^{\circ}$ journal and benefit from:}

- Convenient online submission

- Rigorous peer review

- Open access: articles freely available online

- High visibility within the field

- Retaining the copyright to your article

Submit your next manuscript at $\boldsymbol{\nabla}$ springeropen.com 